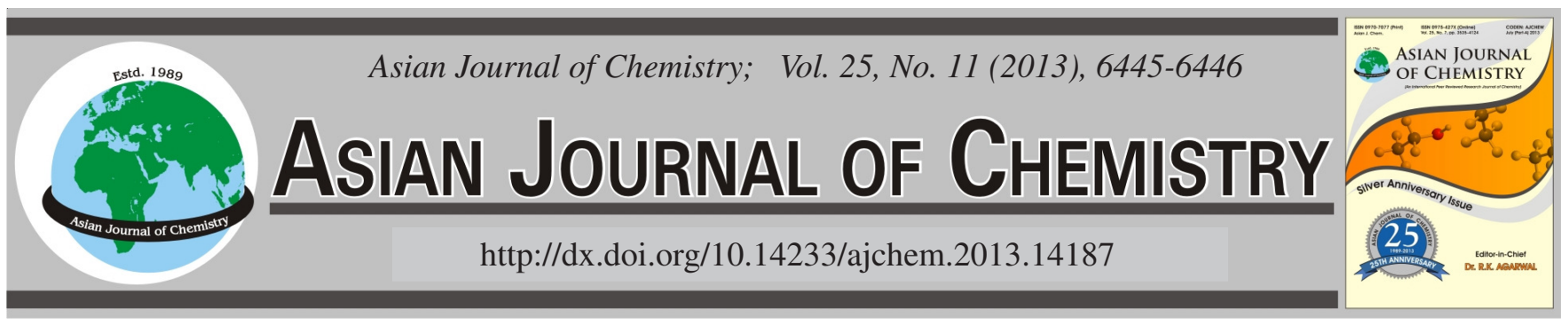

NOTE

\title{
Three-Component One-Pot Synthesis of 4,6-Diarylpyrimidin-2(1H)-ones Catalyzed by 1-Methyl-3-[2-(sulfooxy)ethyl]-1H-imidazol-3-ium Chloride
}

\author{
Yu Wan ${ }^{1}$, Liang-Feng Chen ${ }^{2}$, Hai-Ying Wang ${ }^{2}$, Ling-Ling ZhaO ${ }^{2}$, Shu-Ying Huang ${ }^{2}$, \\ Gui-Xiang Liu'², Shu-Ning Yue ${ }^{2}$, Wen-Li Zhang ${ }^{2}$ and Hui Wu ${ }^{1,2, *}$
}

${ }^{1}$ Key Laboratory of Biotechnology on Medical Plant of Jiangsu Province, Xuzhou 221116, P.R. China

${ }^{2}$ School of Chemistry and Chemical Engineering, Jiangsu Normal University, Xuzhou 221116, P.R. China

*Corresponding author: Fax: +86 516 83500164; Tel: +86 516 83403163; E-mail: wuhui72@yahoo.com.cn

(Received: 8 June 2012;

Accepted: 14 May 2013)

AJC-13489

An efficient, one-pot, three-component cyclocondensation reaction of aromatic aldehydes, aromatic ketone and urea catalyzed by

1-methyl-3-[2-(sulfooxy)ethyl]-1H-imidazol-3-ium chloride is developed to give 4,6-diarylpyrimidin-2(1H)-ones.

Key Words: Synthesis, 4,6-Diarylpyrimidin-2(1H)-ones, 1-Methyl-3-[2-(sulfooxy)ethyl]-1H-imidazol-3-ium chloride.

ᄂ - - - - - - - - - - - - - - - - - - - - - - - - - -

Pyrimidinones is an important class of heterocycles due to their relevance to various biological, pharmaceutical and therapeutic activities ${ }^{1}$, such as anticancer, anti HIV, antibacterial, antimalarial, antihypertensive, sedative, anticonvulsant, antithyroid, antihistaminic activities ${ }^{2-4}$. They are mostly used as calcium channel blockers ${ }^{5,6}, \alpha$-antagonista ${ }^{7}$ and neuropeptideantagonists $^{8}$.

Biginelli ${ }^{9}$ first reported the one-step synthesis of 3,4dihydropyrimidin-2 $(1 H)$-one in alcohol using strong mineral acid. Soon afterwards, various methods were reported concerning the synthesis of pyrimidine derivatives. Few one-pot syntheses have been published using different catalysts such as chlorotrimethylsilane ${ }^{10}, \mathrm{H}_{3} \mathrm{PMo}_{12} \mathrm{O}_{40}{ }^{11}, \mathrm{H}_{6} \mathrm{P}_{2} \mathrm{~W}_{18} \mathrm{O}_{62} \cdot 18 \mathrm{H}_{2} \mathrm{O}^{12}$, sulfamic $\operatorname{acid}^{13}, \mathrm{Bi}(\mathrm{TFA})_{3}$ immobilized in $[\mathrm{nbpy}] \mathrm{FeCl}_{4}{ }^{14}, 2,4,6-$ trichloro-1,3,5-triazine ${ }^{15}$, etc.

Herein, a novel catalyst synthesized in our lab, 1-methyl3-(2-(sulfooxy)ethyl)-1H-imidazol-3-ium chloride (I) was firstly used to promote the simple preparation of 4,6-diarylethenes pyrimidin-2(1H)-ones via an efficient one-step three-component reaction of aromatic aldehyde, aromatic ketone and urea in ionic liquid (Scheme-I).

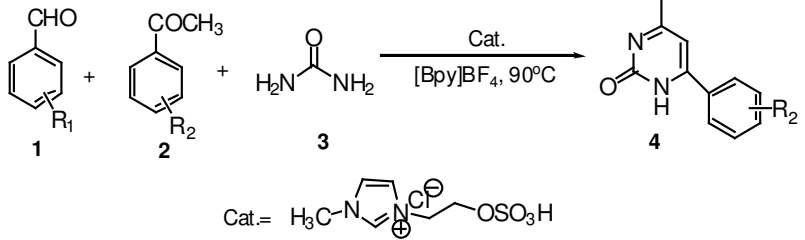

Scheme-I: Synthesis of 4,6-diarylpyrimidin-2(1H)-ones
All melting points are uncorrected and were measured on XT5 melting point apparatus. The ${ }^{1} \mathrm{H}$ and ${ }^{13} \mathrm{C}$ NMR spectra were run on a Bruker Advance DMX 400 spectrometer in $\mathrm{CDCl}_{3}$ using TMS as internal standard. Mass spectra were obtained on a Bruker MicroTOF-QII instrument. The IR spectra were obtained in potassium bromide pellets with a Bruker 27FTIR-Tensor using KBr optics.

Synthesis of 4,6-diarylpyrimidin-2(1H)-ones ${ }^{16}$ : The mixture of aromatic aldehyde $(1 \mathrm{mmol})$, aryl ketone $(1 \mathrm{mmol})$ urea $(4 \mathrm{mmol})$, ionic liquid $(2 \mathrm{~mL})$ and $\mathbf{I}(0.4 \mathrm{~mol} \%)$ were stirred at $90{ }^{\circ} \mathrm{C}$ for the given time. After the completation (monitored by TLC), the mixture was diluted with water. The crude solid was filtered and washed with $95 \% \mathrm{EtOH}$ and then recrystallized with $95 \% \mathrm{EtOH} / \mathrm{DMF}$ (1/4) to provide the pure product 4 (Scheme-I).

Initially, to optimize the reaction condition, the effects of solvents, reaction time and temperature on the yield of $\mathbf{4 b}$ were evaluated and the results were summarized in Table-1. It was found that ionic liquid afforded better yield than other solvents. $[\mathrm{Bpy}] \mathrm{BF}_{4}$ was better than $[\mathrm{Bmim}] \mathrm{BF}_{4}$ may be due to its more suitable polarity and acidity to dissolve the reactants. The appreciable amount of catalyst was $0.4 \mathrm{~mol} \%$. However, the increasing of catalytic loading could not enhance the yield of the product (Table-1, entry 7). Subsequently, the best temperature was investigated. The results in Table- 2 indicated the optimal temperature was $90{ }^{\circ} \mathrm{C}$.

To explore the application of this method, the scope of the substrates was evaluated with a variety of aromatic aldehydes and aromatic ketone (Table-3). 


\begin{tabular}{|c|c|c|c|c|}
\hline \multicolumn{5}{|c|}{$\begin{array}{c}\text { TABLE-1 } \\
\text { SYNTHESIS OF } \mathbf{4 b} \text { UNDER DIFFERENT CONDITIONS }{ }^{\mathrm{a}}\end{array}$} \\
\hline Entry & Solvent & $\begin{array}{l}\text { Catalyst } \\
(\mathrm{mol} \%)\end{array}$ & $\begin{array}{c}\text { Time } \\
(\mathrm{h})\end{array}$ & $\begin{array}{c}\text { Isolated } \\
\text { yield }(\%)\end{array}$ \\
\hline 1 & $\mathrm{CH}_{3} \mathrm{COCH}_{3}$ & 0.4 & 12 & $\mathrm{Nr}^{\mathrm{b}}$ \\
\hline 2 & $\mathrm{EtOH}$ & 0.4 & 12 & $\mathrm{NP}^{\mathrm{c}}$ \\
\hline 3 & DMF & 0.4 & 12 & $\mathrm{Nr}^{\mathrm{b}}$ \\
\hline 4 & $\mathrm{CH}_{3} \mathrm{CN}$ & 0.4 & 12 & $\mathrm{NP}^{\mathrm{c}}$ \\
\hline 5 & THF & 0.4 & 12 & $\mathrm{Nr}^{\mathrm{b}}$ \\
\hline 6 & {$[\mathrm{Bmim}] \mathrm{BF}_{4}$} & 0.4 & 6 & 79 \\
\hline 7 & {$[\mathrm{Bpy}] \mathrm{BF}_{4}$} & 0.4 & 6 & 88 \\
\hline 8 & {$[\mathrm{Bpy}] \mathrm{BF}_{4}$} & 0.6 & 6 & 87 \\
\hline 9 & {$[\mathrm{Bpy}] \mathrm{BF}_{4}$} & 0.5 & 6 & 88 \\
\hline 10 & {$[\mathrm{Bpy}] \mathrm{BF}_{4}$} & 0.3 & 6 & 74 \\
\hline 11 & {$[\mathrm{Bpy}] \mathrm{BF}_{4}$} & 0.2 & 6 & 62 \\
\hline 12 & {$[\mathrm{Bpy}] \mathrm{BF}_{4}$} & 0.1 & 6 & 53 \\
\hline
\end{tabular}

aReaction condition: 3,4-dimethoxybenzaldehyde (1 mmol), 4nitroacetophenone $(1 \mathrm{mmol})$, and urea $(4 \mathrm{~mol})$ in $2 \mathrm{~mL}$ of different solvents at $90{ }^{\circ} \mathrm{C}$ using $0.4 \mathrm{~mol} \% 0.4 \mathrm{~mol} \%$ of I as catalyst. ${ }^{\text {b }} \mathrm{No}$ reaction. ${ }^{\mathrm{N}}$ No desired products.

\section{TABLE-2}

SYNTHESIS OF 4b AT DIFFERENT TEMPERATURE

\begin{tabular}{ccc}
\hline Entry & $\mathrm{T}\left({ }^{\circ} \mathrm{C}\right)$ & Isolated yield $(\%)$ \\
\hline 1 & r.t & $\mathrm{Nr}^{\mathrm{b}}$ \\
2 & 60 & $\mathrm{Nr}^{\mathrm{b}}$ \\
3 & 80 & 64 \\
4 & 90 & 88 \\
5 & 100 & 88 \\
6 & 110 & 86 \\
\hline
\end{tabular}

"aReaction condition: 4-nitroacetophenone (1 $\mathrm{mmol}), \quad 3,4-$ dimethoxybenzaldehyde $(1 \mathrm{mmol})$ and urea $(4 \mathrm{mmol})$ in $[\mathrm{Bpy}] \mathrm{BF}_{4}$ at different temperature for $6 \mathrm{~h}$ catalyzed by $0.4 \mathrm{~mol} \%$ of $\mathbf{I}$. ${ }^{\mathrm{b}}$ No reaction.

\begin{tabular}{ccccc}
\multicolumn{5}{c}{ TABLE-3 } \\
SYNTHESIS OF 4 \\
Comp. & $\mathrm{R}_{1}$ & $\mathrm{R}_{2}$ & $\begin{array}{c}\text { Time } \\
\text { (h) }\end{array}$ & $\begin{array}{c}\text { Isolated } \\
\text { yield (\%) }\end{array}$ \\
\hline $\mathbf{4 a}$ & $2-\mathrm{OCH}_{3}$ & $4-\mathrm{NO}_{2}$ & 6 & 85 \\
$\mathbf{4 b}$ & $3,4-\left(\mathrm{OCH}_{3}\right)_{2}$ & $4-\mathrm{NO}_{2}$ & 6 & 88 \\
$\mathbf{4 c}$ & $4-\mathrm{OCH}_{3}$ & $4-\mathrm{NO}_{2}$ & 5 & 86 \\
$\mathbf{4 d}$ & $3-\mathrm{Br}_{4}$ & $4-\mathrm{NO}_{2}$ & 6 & 87 \\
$\mathbf{4 e}$ & $3-\mathrm{NO}_{2}$ & $4-\mathrm{NO}_{2}$ & 7 & 85 \\
$\mathbf{4 f}$ & $3,4,5-\left(\mathrm{CH}_{3} \mathrm{O}\right)_{3} \mathrm{C}_{6} \mathrm{H}_{2}$ & $4-\mathrm{NO}_{2}$ & 6 & 86 \\
$\mathbf{4 g}$ & $4-\mathrm{OH}$ & $4-\mathrm{NO}_{2}$ & 6 & 84 \\
$\mathbf{4 h}$ & $4-\mathrm{Br}$ & $4-\mathrm{Cl}$ & 6 & 85 \\
$\mathbf{4 i}$ & $4-\mathrm{I}$ & $4-\mathrm{Cl}$ & 6 & 86 \\
$\mathbf{4 j}$ & $3,4,5-\left(\mathrm{CH}_{3} \mathrm{O}\right)_{3} \mathrm{C}_{6} \mathrm{H}_{2}$ & $4-\mathrm{Cl}$ & 7 & 87 \\
$\mathbf{4 k}$ & $3,4-\left(\mathrm{OCH}_{3}\right)_{2}$ & $3-\mathrm{OH}$ & 6 & 86 \\
$\mathbf{4 l}$ & $4-\mathrm{I}$ & $3-\mathrm{OH}$ & 6 & 87 \\
$\mathbf{4 m}$ & $4-\mathrm{Cl}_{4}$ & $\mathrm{H}$ & 6 & 85 \\
$\mathbf{4 n}$ & $4-\mathrm{OCH}_{3}$ & $\mathrm{H}$ & 7 & 83 \\
\hline
\end{tabular}

aReaction condition: aromatic aldehydes $(1 \mathrm{mmol})$, aromatic ketone $(1 \mathrm{mmol})$ and urea $(4 \mathrm{mmol})$ in $2 \mathrm{~mL}$ of $\left[\mathrm{Bpy}_{\mathrm{B}}\right] \mathrm{BF}_{4}$ at $90{ }^{\circ} \mathrm{C}$ catalyzed by $0.4 \mathrm{~mol} \%$ of $\mathbf{I}$.

The possible reaction mechanism was proposed in Scheme-II. It is presumed that the reaction proceeds via initial Aldol addition of aromatic aldehyde with aryl ketone to give a chalcone, which addition with urea to give intermediate $\mathrm{C}$. The cyclization and dehydration of $\mathrm{C}$ give products 4 .

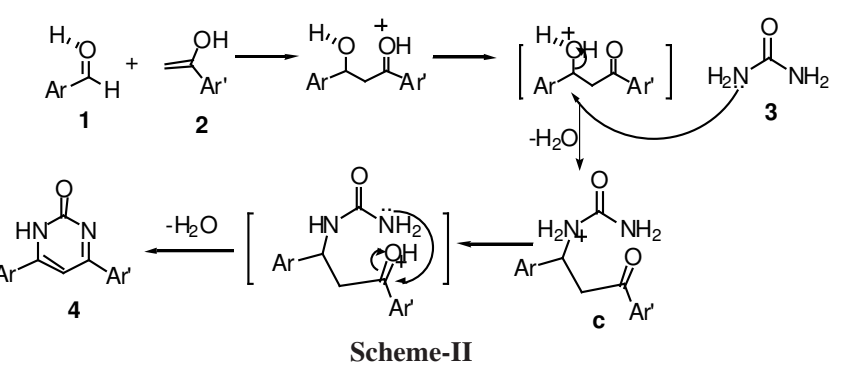

In summary, we report here a high yield one-pot synthesis of 4,6-diarylpyrimidin-2(1H)-ones, from readily available aromatic aldehydes, aromatic ketones and urea catalyzed by 1-methyl-3-[2-(sulfooxy)ethyl]-1H-imidazol-3-ium chloride. This new protocol provides an environmentally benign route along with the associated advantages of simplicity of operation and higher atomic efficiency.

\section{ACKNOWLEDGEMENTS}

The authors are grateful to the foundation of the Priority Academic Program Development of Jiangsu Higher Education Institutions, Qing Lan Project in Jiangsu Province (No. 08QL001T), Key Basic Research Project in Jiangsu University (No. 10KJA430050), the Post-Graduate Innovation Project in Jiangsu Province (No. CXZZ12_0979) and the Natural Science Foundation of Jiangsu Normal University (No. 09XLA17, No. 09XLB05) for financial support.

\section{REFERENCES}

1. P. Salehi, M. Dabiri, A.R. Khosropour and P. Roozbehniya, J. Iran. Chem. Soc., 3, 98 (2006).

2. D. Russowsky, E.V. Benvenutti, G.S. Roxo and F. Grasel, Lett. Org. Chem., 4, 39 (2007).

3. N. Rameshwar, T. Parthasarathy and A.R. Reddy, Indian J. Chem., 47B, 1871 (2008).

4. T.B. Shah, A. Gupte, M.R. Patel, V.S. Chauhari, H. Patel and V.C. Patel, Indian J. Chem., 48B, 88 (2009).

5. C.O. Kappe, Eur. J. Med. Chem., 35, 1043 (2000).

6. B. Gangadasu, P. Narender, B.C. Raju and V.J. Rao, Indian J. Chem., 45B, 1259 (2006).

7. K.S. Atwal, B.N. Swanson, S.E. Umger and D.M. Floyd, S. Moreland, A. Hedberg and B.C. O'Reilly, J. Med. Chem., 34, 806 (1991).

8. S. Bartolini, A. Mai, M. Artico, N. Paesano, D. Rotili, C. Spadafora and G. Sbardella, J. Med. Chem., 48, 6776 (2005).

9. G. Biginelli, Chim. Ital., 23, 360 (1893).

10. L.Z. Wang, X.Q. Bian, H. Liu, Q. Sun and C.D. Wang, J. Chem. Res., 34, 694 (2010).

11. Z. Pourghobadi and F. Derikvand, Chin. Chem. Lett., 21, 269 (2010).

12. M.M. Heravi, F. Derikvand and L. Ranjbar, Synth. Commun., 40, 1256 (2010).

13. M.M. Heravi, L. Ranjbar, F. Derikvand, B. Alimadadi and H.A. Oskooie, Mol. Divers, 12, 191 (2008).

14. A.R. Khosropour, I. Mohammadpoor-Baltork and H. Ghorbankhani, Catal. Commun., 7, 713 (2006)

15. A.R. Khosropour, B.I. Mohammadpoor and J. Mahbubeh, Heterocycles, 68, 1551 (2006).

16. H. Wu, Y. Wan, X.M. Chen, C.F. Chen, L.-L. Lu, H.-Q. Xin, H.-H. Xu, L.-L. Pang, R. Ma and C.-H. Yue, J. Heterocycl. Chem., 46, 702 (2009). 